\title{
Evolutionary Arbitrage For FTSE-100 Index Options and Futures
}

\author{
Sheri Markose\#, Edward Tsang*, Hakan Er\#, Abdel Salhi** \\ \#Economics, *Computer Science and **Mathematics Department \\ University of Essex, Colchester, Essex CO4 3SQ, UK \\ http://cswww.essex.ac.uk/CSP/finance
}

\begin{abstract}
The objective in this paper is to develop and implement FGP-2 (Financial Genetic Programming) on intra daily tick data for stock index options and futures arbitrage in a manner that is suitable for online trading when windows of profitable arbitrage opportunities exist for short periods from one to ten minutes. Our benchmark for FGP-2 is the textbook rule for detecting arbitrage profits. This rule has the drawback that it awaits a contemporaneous profitable signal to implement an arbitrage in the same direction. A novel methodology of randomised sampling is used to train FGP-2 to pick up the fundamental arbitrage patterns. Care is taken to fine tune weights in the fitness function to enhance performance. As arbitrage opportunities are few, missed opportunities can be as costly as wrong recommendations to trade. Unlike conventional genetic programs, FGP-2 has a constraint satisfaction feature supplementing the fitness function that enables the user to train the FGP to specify a minimum and a maximum number of profitable arbitrage opportunities that are being sought. Historical sample data on arbitrage opportunities enables the user to set these minimum and maximum bounds. Good FGP rules for arbitrage are found to make a 3-fold improvement in profitability over the textbook rule. This application demonstrates the success of FGP-2 in its interactive capacity that allows experts to channel their knowledge into machine discovery.
\end{abstract}

\section{Introduction}

Genetic Programming (GP) (Koza 1992, 1994; Koza et al 1996) is a promising variant of genetic algorithms (Holland 1975, Goldberg 1989, Mitchell 1996) especially for financial applications as it uses decision tree representations instead of strings of chromosomes. The decision tree representations referred to as Genetic Decision Trees (GDTs) will be able to handle rule sets of variable size ${ }^{1}$ and these rules are easy to understand and evaluate by human users. This makes this approach more attractive than neural networks, most of which are black boxes (Goonatilake and Treleaven, 1995).

Genetic algorithms have been studied in financial markets for a number of years. Bauer (1994) reported

\footnotetext{
${ }^{1}$ Typically, in contrast genetic algorithms that operate with strings use strings of fixed lengths.
}

on his GAs intelligent systems which aimed at finding tactical market timing strategies; Allen \& Karjalainen (1995) applied Genetic Programming to find profitable technical trading rules for the S\&P 500 index; Chen \& Yeh (1996) attempted to formalize the notion of unpredictability in the efficient market hypothesis in terms of search intensity and chance of success in the search conducted by genetic programming; Mahfoud \& Mani (1996) presented a new genetic-algorithm-based system and applied it to the task of predicting the future performances of individual stocks; Neely et al. (1997) and Oussaidene et al. (1997) applied genetic programming to foreign exchange forecasting and reported some success.

In earlier work (Tsang et al. 1998, Li \& Tsang 1999a and $\mathrm{Li} \&$ Tsang 1999b) reported some of preliminary but promising results obtained from using a tool called FGP-1 (which stands for Financial Genetic Programming). FGP-1 was used specifically to predict whether a price series will increase by $r \%$ or more within the next $n$ periods. FGP was found to compare favourably with random rules, commonly used individual technical rules and $\mathrm{C} 4.5$ rule sets with respect to prediction accuracy and average annualised rate of return.

The objective in this paper is to develop and implement FGP-2 on intra daily tick data for stock index options and futures arbitrage in a manner that is suitable for online trading when windows of profitable arbitrage opportunities exist for short periods from one to ten minutes. Recent work by Markose and Er (2000) on the FTSE-100 stock index options clearly indicate that options that are far from maturity with even fewer than 40 days can present arbitrage opportunities. As the arbitrageur maximizes return by exploiting as many profitable arbitrage opportunities and avoiding as many positions that are loss making, we will show how the fitness function of FGP-2 will enable the arbitrageur to 'tune' it to obtain the most favourable trade off. In other words, in arbitrage activity avoiding positions that are loss making or minimizing rate of failure (RF) alone which was the focus of earlier work by Tsang et. al. is not sufficient. However, before we give the details of this we will first outline in Section 2 the methodology for processing the intra daily tick data in the format in which arbitrage opportunities can be contemporaneously detected for the purposes of training and testing the FGP-2 program. In Section 3 , we give some details of the FGP and how the fitness 
function has to be fine tuned to obtain the favourable trade off between exploiting arbitrage opportunities and loss making recommendations. Section 4 reports the empirical results of the application of FGP for stock index arbitrage trading. In the first instance all the steps taken to pre-process the arbitrage price data in a manner in which FGP can perform effectively have been reported. Our benchmark for FGP performance is the textbook rule for detecting arbitrage profits. This has the drawback that it awaits a contemporaneously profitable signal to implement an arbitrage in the same direction. Good FGP rules are found to make 3 fold improvement in profitability.

\section{Methodology of Put-Call-Futures Stock Index Arbitrage}

Arbitrage in stock index options is based on strategies that can bypass the cash leg of the spot stock index market which is prohibitively expensive. As the FTSE100 spot index has a stock index futures and a European style index option traded on it, the most cost effective arbitrage is one that involves the two stock index derivatives with the same maturity date. The arbitrage strategy resulting in an equilibrium relationship between the index futures and the index options is called the put-call-futures parity (P-C-F, for short) relationship and was first discussed by Tucker (1991). As futures positions can be replicated by combinations of call and put options, the P-C-F no arbitrage equilibrium pricing relationship is based on the index futures price being close to the synthetic futures price.

\section{P-C-F Short Hedge Arbitrage}

A risk free arbitrage portfolio can be constructed by combining a short futures contract and a long synthetic futures position by buying a call, shorting a put and by borrowing the present discounted value of the futures price and lending the same for the exercise price. Panel A in Table 1 shows how a zero net return is ccomplished by this short hedge arbitrage strategy should $\mathrm{S}_{\mathrm{T}}>\mathrm{E}$ or $\mathrm{S}_{\mathrm{T}}<\mathrm{E}$. The upper bound of the FTSE-100 index futures bid price denoted by $\mathrm{F}_{\mathrm{bt}}$ is given by

$$
\mathrm{F}_{b t} \mathrm{e}^{\mathrm{r}_{\mathrm{a}}(\mathrm{t}-\mathrm{T})}<\mathrm{C}_{\mathrm{at}}-\mathrm{P}_{\mathrm{bt}}+X \mathrm{e}^{\mathrm{r}_{\mathrm{b}}(\mathrm{t}-\mathrm{T})}+\Gamma \text {. }
$$

Here, (T-t) is the remaining time to maturity; $\mathrm{C}_{\mathrm{at}}$ is the call premium at the ask, $\mathrm{P}_{\mathrm{bt}}$ is the put premium at the bid and $\Gamma$ denotes the transactions costs (that will be specified) that exist in the futures and option markets. Note the interest rate on the futures price is the offer/ask rate as this amount has to be borrowed by the arbitrageur and that on the exercise price is the bid interest rate as it has to lent. If this condition is violated then the arbitrageur by definition will make a risk free profit equal to

$$
\left[F_{b t} e^{r_{a}(t-T)}-\left(C_{a t}-P_{b t}+X e^{r_{b}(t-T)}+\Gamma\right)\right]
$$

by shorting the futures and by creating the synthetic long futures given on the R.H.S of (1).

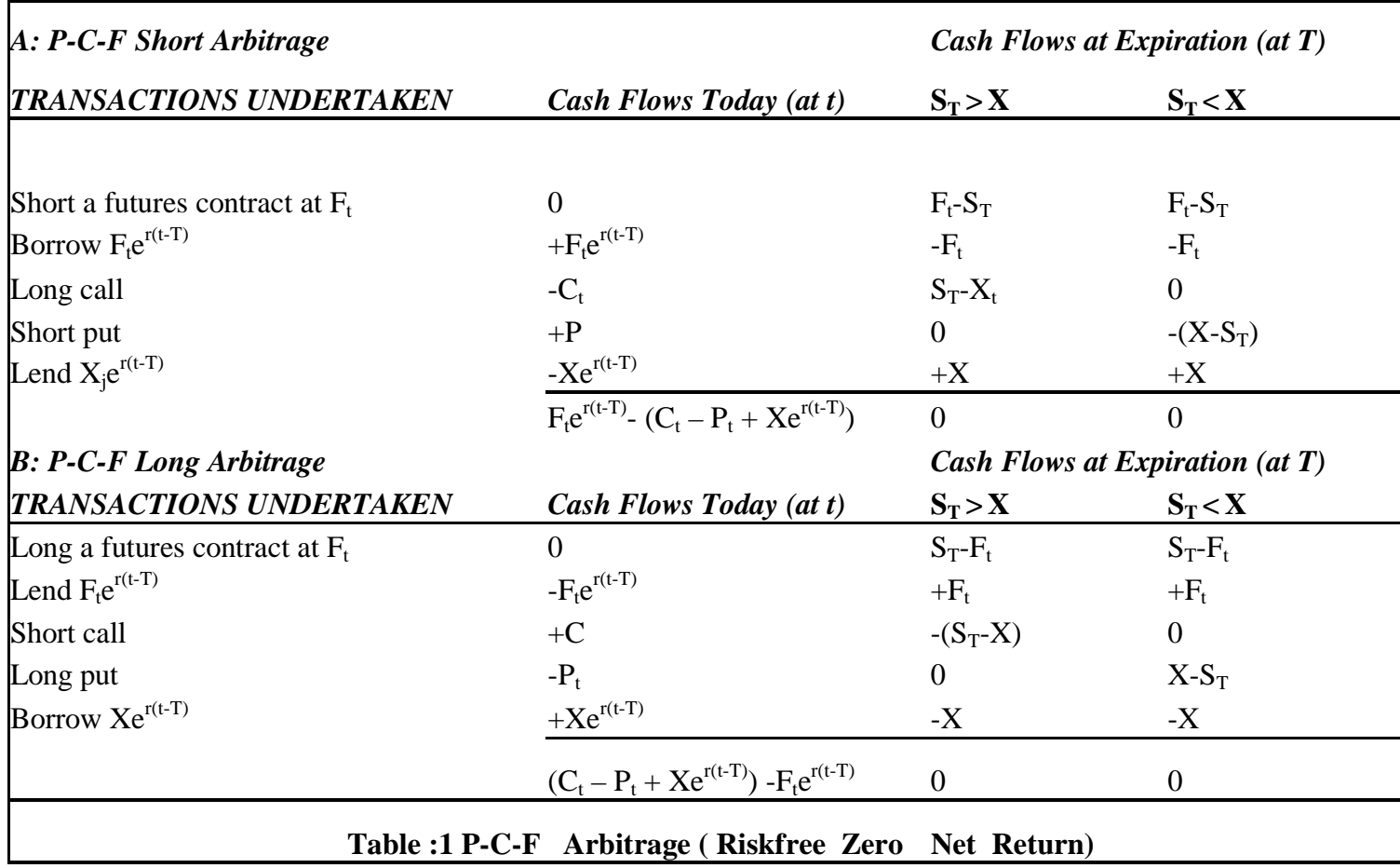




\section{LIFFE Intradaily Trade Data for Index Options and Futures Arbitrage}

We first take the intraday historical tick data on the FTSE-100 index futures and the European style index options traded on the LIFFE from January 1, 1991 to June 30, 1998.

The risk free interest rate used for borrowing funds in the hedge portfolio is the London Interbank Offer Rate (LIBOR) maturing on the day closest to the expiration date of the option. FTSE-100 index spot prices are obtained from Data Stream. The bid or lending interest rate is conventionally taken to be $1 / 8$ of the LIBOR rate.

To obtain tick data for arbitrage relating to the putcall-futures parity, we follow a three way matching criteria for puts, calls and futures with the same nearby maturity. For trade data, calls and puts with the same exercise price and traded within the same minute are matched. This pair is matched further with a futures contract traded within a minute of the time stamp of the call-put pair. We focus on short arbitrage conducted by broker/market maker who is estimated to have transactions costs of less than $.1 \%$ value of the value FTSE100 index futures contract. This is approximately about $£ 60$ per P-C-F arbitrage.

In the LIFFE tick data from January 1991 to June 1998, 1709 arbitrage trade price triplets were found in the trade data. For traded price triplets of the calls, puts and futures the null hypothesis for the absence of short arbitrage is given by

$$
F e^{r(t-T)}-\left[C_{t}-P_{t}+X e^{r(t-T)}\right] \leq 0 .
$$

\subsection{Ex Ante Analysis of Arbitrage Profits and} Application of FGP

The standard ex ante analysis of arbitrage addresses a number of issues. The naïve premise is that the arbitrageur waits for a contemporaneous profit signal in the category of either short or long arbitrage (given in Table 1) above and then continues with arbitrage trades in the same direction in say a given time interval. If there are time delays in execution of an arbitrage from an observed contemporaneous profit signal, it is sometimes too late to exploit the arbitrage opportunities in the next relevant time interval. The question we ask of FGP is: at any point in time corresponding with the occurrence of a matched P-C-F price triplet, how many adjacent 10 minute intervals can it predict as being profitable for arbitrage in a given direction after a one minute execution delay. Note the recommended arbitrage positions are judged profitable or not by the criteria given in equations relating to Table 1 . However, as indicated in the introduction, the FGP implements a trade off between missed profit opportunities and loss making recommendations.

\subsection{Background of FGP}

Like other standard GAs, FGP maintains a population (set) of candidate solutions, each of which is a decision tree for financial forecasting. Candidate solutions are selected randomly, biased by their fitness, for involvement in generating members of the next generation. General mechanisms (referred to as genetic operators, e.g. reproduction, crossover, mutation) are used to combine or change the selected candidate solutions to generate offspring, which will form the population in the next generation. For details of GA and GP, readers are referred to Holland (1975), Goldberg (1989) and Koza (1992).

In FGP, a candidate solution is represented by a genetic decision tree (GDT). The basic elements of GDTs are rules and forecast values. A single rule is consisted of one useful indicator for prediction, one relational operator such as "greater than", or "less than", etc, and a threshold (real value). Such a single rule interacts with other rules in one GTD through logic operators such as "Or", "And", "Not", and "If-ThenElse". Forecast values in this example are either a positive position (i.e. positive return within specified time interval can be achievable) or negative position (i.e. negative return within a specified time interval will be achievable).

\subsection{The FGP Fitness Criterion}

Since GDTs are used to predict whether a profitable arbitrage can exist from any point in time and within the next 10 minutes, the prediction actually can be categorised as a two-class classification problem. Each time point can be classified into either a positive position or a negative position. For each GDT, we define RC (Rate of Correctness), RMC (Rate of Missed Opportunities), and RF (Rate of Failure) as its prediction performance criteria. Formula for each criterion is given through a contingency table (Table 2) as follows:

\begin{tabular}{|c|c|c|}
\hline $\begin{array}{l}\text { Predicted } \\
\text { negative } \\
\text { positions (N-) }\end{array}$ & $\begin{array}{l}\text { Predicted } \\
\text { positive } \\
\text { positions }\left(\mathrm{N}_{+}\right)\end{array}$ & \\
\hline $\begin{array}{l}\text { \# of True } \\
\text { Negative }(\boldsymbol{T N})\end{array}$ & $\begin{array}{l}\text { \# of False } \\
\text { Positive }(\boldsymbol{F P})\end{array}$ & $\begin{array}{l}\text { Actual negative } \\
\text { positions }\left(\mathrm{O}_{\text {. }}\right)\end{array}$ \\
\hline $\begin{array}{l}\text { \# of False } \\
\text { Negative }(\boldsymbol{F N})\end{array}$ & $\begin{array}{l}\text { \# of True } \\
\text { Positive }(\boldsymbol{T P})\end{array}$ & $\begin{array}{l}\text { Actual positive } \\
\text { positions }\left(\mathrm{O}_{+}\right)\end{array}$ \\
\hline
\end{tabular}

Table 2 Contingency Table for Two-Way Classification Prediction Problem

$$
\begin{aligned}
& \mathbf{R C}=\frac{T P+T N}{O_{+}+O_{-}}=\frac{T P+T N}{N_{+}+N_{-}} ; \\
& \mathbf{R M C}=\frac{F N}{O_{+}} ; \quad \mathbf{R F}=\frac{F P}{N_{+}} ; \\
& \text {Where } O_{+}=F N+T P ; O_{-}=T N+F P ; \quad N_{-}=T N+F N ; \\
& N_{+}=F P+T P .
\end{aligned}
$$




\section{A: Linear Fitness Function}

In earlier work by Tsang et. al., the fitness function mainly used in FGP was RC (Rate of Correctness). By using the following fitness function, the user may satisfy individual objectives by adjusting the weights w_rc, w_rmc and w_rf:

$$
f_{(1)}=w_{-} r c * R C-w_{-} r m c * R M C-w_{-} r f * R F
$$

It involves three performance values, i.e. RC, RMC and RF, each of which is assigned a different weight. Obviously, the performance of a GDT is no longer assessed by RC only, but by a synthetic value, which is the weighted sum of its three performance rates. By proper adjustment of the three weights, one is able to place emphasis on one performance rate than on the others. In order to achieve a low RF, one may assign a higher value to $w_{-} r c$ and $w_{-} r f$ and a smaller or zero value to $w_{-} r m c$.

To a certain extent, the fitness function $f_{(1)}$ does allow us to reduce RF. However, it has two drawbacks: 1) FGP's performance is very sensitive to the three weights; 2) results are unstable. For example, in one of our series of preliminary experiments we used the following three weights:

$$
w_{-} r c=1 ; \quad w_{-} r m c=0 \text { and } w_{-} r f=\alpha
$$

where $0<\alpha \leq 1$.

We found that a slightly bigger $\alpha$ almost always resulted in a GDT that did achieve a lower RF (even zero over training period) by making no positive recommendations over the test period. This was probably due to over-fitting. In contrast, a slightly smaller $\alpha$ usually resulted in generating GDT that it did not show any improvement on RF. We refer to this as the no-effect problem. Even though a plausible $\alpha$ was found (e.g. $\alpha=0.62$ ), it does not generate effective GDTs reliably. For example, among 10 runs, only two runs generated a GDT that predicted a few correct positive positions on the test period. The remaining 8 runs showed either the over-fitting or no-effect problem.

\section{B:Putting constraints into FGP}

We can further improve the linear fitness function $f_{(1)}$ by introducing constraints into it. We introduce a new parameter to FPG, $\mathfrak{R}=\left[\mathrm{P}_{\min }, \mathrm{P}_{\max }\right]$, which defines the minimum and maximum percentage of recommendations that we instruct FGP to make in the training data (with the assumption that the test data exhibits similar characteristics, as most machine learning methods do). We call the new fitness function $f_{(2)}$.

Choosing appropriate values for $\mathfrak{R}$ and the weights for $f_{(2)}$ remains a non-trivial task, which we approached by trial and error. When appropriate parameters were chosen, FGP managed to reduce RF and avoid the over- fitting and no-effect problems. The results here are discussed in the next section.

\section{Experimentation-Results}

\subsection{Pre-processing of the Arbitrage Data}

The objective of these tests is to compare the effectiveness of GDT generated by FGP-2 against a naïve arbitrage rule which signals an arbitrage trade whenever there is a contemporaneous profit. The short arbitrage trade data that was first fed into FGP included the strike price, the call premium, the put premium, the underlying index value, futures price, time to maturity of the contract, profit after transactions costs. The total number of observations is 8073. FGP did not give any recommendations on this set.

The data was then altered to be more informative in terms of economic theory. The strike price, was converted into the 'moneyness' variable, viz. as the ratio of the undelying to the strike price. This variable is introduced as ' in', 'at' and 'out' of the money for call and put options has an impact on the arbitrage profits. The second variable added was basis, the formula for basis is as follows:

\section{basis=(futures-underlying)/futures}

This variable controls for the mispricing in the futures leg of the arbitrage. Call minus Put price (C-P) is also added to the model. Finally, the following variables, the underlying, C-P and profit after transaction costs were input as a percentage of the futures price.

The results of a preliminary run on this data set are summarized below in Table 3 .

In Table 3, we see that as the RF(Rate of Failure) was so high and the prediction accuracy of the recommendations made by FGP was so low, therefore we decided to further process the data. Indeed, we recommend the following methodology for training good FGP rules due to some typical problems associated with arbitrage opportunities and the time execution delay. number of the rows reduced to 1641 .

\subsection{Methodology for Training FGP With Historical Tick Arbitrage Data}

1. The distribution of contemporaneous P-C-F arbitrage signals is given in Table 4 (in the Appendix) in terms of contracts and profitability evaluated after transactions costs. In the LIFFE FTSE-100 PCF arbitrage triplets, it is clear that arbitrage 


\begin{tabular}{|c|c|c|c|c|c|c|c|c|c|}
\hline \multirow{2}{*}{\multicolumn{2}{|c|}{$\begin{array}{l}\text { Training } 4178 \\
29 \text { Jan } 91 \text { To }\end{array}$}} & Rows & From & 3 & To & 4180 & & FGP & Naïve \\
\hline & & \multicolumn{5}{|c|}{20 Dec 96 Contingency Table for Selected Data } & Sum & 122727 & 147257.2 \\
\hline $\mathrm{RC}$ & $\mathrm{RMC}$ & $\mathrm{RF}$ & 0 & 1 & & & Count & 2949 & 1848 \\
\hline \multirow[t]{3}{*}{$94.18 \%$} & $64.66 \%$ & $80.38 \%$ & 3894 & 168 & 0 & 4062 & AvePro & 41.62 & 79.68 \\
\hline & & & 75 & 41 & 1 & 116 & & & \\
\hline & & & 3969 & 209 & $5.00 \%$ & 4178 & $2.78 \%$ & & \\
\hline Testing & 3895 & Rows & From & 4181 & To & 8075 & \multirow{6}{*}{$\begin{array}{l}\text { R.C:Rate } \\
\text { R.F:Rate } \\
\text { RMC:Rate }\end{array}$} & & \\
\hline 2 Jan 97 & To & 18 Jun & Contir & cy Ta & le for Sel & ted Data & & Correct & \\
\hline $\mathrm{RC}$ & RMC & RF & 0 & 1 & & & & Failure & \\
\hline \multirow[t]{3}{*}{$27.55 \%$} & $27.72 \%$ & $93.01 \%$ & 867 & 2743 & 0 & 3610 & & Missed & Chances \\
\hline & & & 79 & 206 & 1 & 285 & & & \\
\hline & & & 946 & 2949 & $75.71 \%$ & 3895 & & & \\
\hline
\end{tabular}

Table 3 Preliminary FGP Run

opportunities were sparse in the early years from 1991-1994 with December contracts being the most voluminous. As trading volume in the index options increased, we have a three fold increase of P-C-F arbitrage opportunities by 1994 and by the end of 1998, there is over a tenfold increase since the inception of electronic index options trading in LIFFE. On average the numbers of profitable P-C$\mathrm{F}$ arbitrage opportunities are far outnumbered by loss making P-C-F opportunities in all years. However, in the years after 1995, the average total profitability of P-C-F positions become positive with the loss making arbitrages generating smaller losses than the gainful ones. In other words, the returns to P-C-F arbitrage are significant if the arbitrageur can successfully 'pick' the cherry.

2. The naïve rule recommends that any profitable PC-F signal is followed by an arbitrage in the same direction in a 9 minute window after a one minute execution delay. In the early years, the sparseness of P-C-F arbitrage price triplets meant that the few contemporaneous profitable signals that existed do not have follow ups in the given 10 minute window. Many of those that did have loss making follow ups. In fact only $20 \%$ of the total sample of P-C-F triplets have any follow ups at all. It is only after 1996 that there are profitable follow ups from any P-C-F time stamp.

3. The above problem indicates that the FGP be trained in the $20 \%$ of the total sample of short arbitrage P-C-F price triplets that have follow ups in the given window of opportunity. Thus, the sample size is reduced to 1641 . Unlike the naïve arbitrage strategy, FGP has to predict profitable follow up trades in the prescribed time window from any given time stamp of a P-C-F price triplet.

4. The follow up based sample of 1641 lines is divided into test and training areas using a randomized procedure rather than that is time based on a time series. Each P-C-F triplet is assigned a random number between 0 to 1 . If the random number for the triplet is less than 0.63 then that triplet is included in the training part of the sample. All of the remaining triplets, i.e. the triplets with a random number greater than 0.63 , were included in the test part. This sampling procedure ensured that we have enough observations in the training part for FGP to function properly ( the recommended minimum for training FGP is 1000 observations). This sampling has also resulted in an equal distribution of arbitrage opportunities in training and test areas to counter the problems raised in point 1 .

\subsection{FGP Rules and Profit Performance}

The FGP runs trained on this randomized data set provided good results. The results are summarized in Table 5 which has results from four settings of the maximum and minimum constraints specified in the fitness function $f_{2}\left(\mathfrak{R}=\left[\mathbf{P}_{\min }, \mathbf{P}_{\max }\right]\right)$.

As we move from a more conservative setting to a more ambitious one, $\mathrm{RF}$ (Rate of Failure) increases and RMC(Rate of Missed Chances) decreases. In every setting, the decision rules generated by FGP beat naïve strategy which provides 196 arbitrage signals, $£ 66,266.17$ total profit, and $£ 338.10$ average profit in the test area. The average profit generated by GDTs are highest when the most conservative setting is applied for the tests. However, the total profit increases with the ambitiousness level ( $\mathrm{P}_{\max }$ is increased). For instance as the number of missed opportunities are minimized with the ambitiousness parameters rising to 20-25, (Table $5 \mathrm{D}$ in Appendix) with the exception of three cases, all GDTs produce total profits in excess of $£ 66,266.17$ which is obtained from the naïve rule. Indeed, the best rule (GDT 4) produces 154 arb. signals and $£ 112683.86$ in total profits, and £731.71in average profit in the test area.

\section{Acknowledgements}

This research is partially supported by the Research Promotion Fund, University of Essex. 


\section{Bibliography}

[1] Allen, F. \& Karjalainen, R. (1995), Using Genetic Algorithms to find Technical Trading Rules. Working paper at Rodney L. White Center for Financial Research.

[2] Alexander, S.S., (1964), Price movement in speculative markets: trend or random walks, No. 2, in Cootner, P. (ed.), The random character of stock market prices, MIT Press, Cambridge, MA, 338-372.

[3] Backus, J.W., (1959), "The syntax and semantics of the proposed international algebraic language of Zurich”, ACM-GAMM conference, ICIP, Paris, June.

[4] Bauer, R. J. Jr., (1994), Genetic Algorithms and Investment Strategies. New York, John Wiley \& Sons, Inc.

[5] Brock, W., Lakonishok, J. \& LeBaron, B., (1992), Simple technical trading rules and the stochastic properties of stock returns, Journal of Finance, 47, 1731-1764.

[6] Chen, S-H \& Yeh, C-H. , (1996), Toward a computable approach to the efficient market hypothesis: An application of genetic programming, Journal of Economic Dynamics and Control, 21, 1043-1063.

[7] Fama, E.F. \& Blume, M.E., (1966), Filter rules and stock-market trading, Journal of Business 39(1), 226-241.

[8] Goldberg, D.E., (1989), Genetic Algorithms in Search, Optimization and Machine Learning. Addison-Wesley.

[9] Holland, J.H., (1975), Adaptation in natural and artificial system, University of Michigan Press.

[10] Koza, J.R., (1992), Genetic Programming: on the programming of computers by means of natural selection. MIT Press.

[11] Koza, J.R., (1994), Genetic Programming II: Automatic Discovery of Reusable Programs. MIT Press.

[12] Koza, J., Goldberg, D., Fogel, D. \& Riolo, R. (ed.), Proceedings of the First Annual Conference on Genetic programming, MIT Press, 1996.
[13] Li, J. \& Tsang, E.P.K, (1999a), Improving technical analysis predictions: an application of genetic programming, Proceedings of The 12th International Florida AI Research Society Conference, Orlando, Florida, May 1-5, 1999, 108-112.

[14] Li, J. \& Tsang, E.P.K, (1999b), Investment decision making using FGP: a case study, Proceedings of Congress on Evolutionary Computation (CEC'99), Washington DC, USA, July 6-9 1999.

[15] Mahfoud, S. \& Mani, G., (1997), Financial Forecasting Using Genetic Algorithms, Journal of Applied Artificial Intelligence Vol.10, Num 6, 543-565.

[16] Mitchell, M., (1996), An Introduction to Genetic Algorithms. MIT Press.

[17] Markose, S. and H. Er, 2000, 'An examination of put-call-futures parity on LIFFE Index futures and options', mimeo, Economics Department, University of Essex.

[18] Neely, C., Weller, P. \& Ditmar, R., (1997), Is technical analysis in the foreign exchange market profitable? A genetic programming approach, Journal of Financial and Quantitative Analysis, $32,405-26$.

[19] Oussaidene, M., Chopard, B., Pictet, O. \& Tomassini, M., (1997), Practical aspects and experiences - Parallel genetic programming and its application to trading model induction, Journal of Parallel Computing Vol. 23, No. 8, 1183-1198.

[20] Saad, E., Prokhorov, D., and Wunsch, D., (1998), Comparative study of stock trend prediction using time delay, recurrent and probabilistic neural networks, IEEE Transactions on Neural Networks, vol. 9. 1456-1470.

[21] Sweeney, R.J., (1988), "Some new filter rule tests: Methods and results," Journal of Financial and Quantitative Analysis, 23, 285-300.

[22] Tsang, E.P.K., Li, J. \& Butler, J.M., (1998), EDDIE beats the bookies, International Journal of Software, Practice \& Experience, Wiley, Vol.28 (10), 1033-1043. 


\section{Appendix}

\begin{tabular}{|c|c|c|c|c|c|c|c|c|c|c|}
\hline Date & All & Count & Average & $\begin{array}{l}\text { Total } \\
\text { Positive } \\
\text { Profit }\end{array}$ & Count & Average & $\begin{array}{l}\text { Total } \\
\text { Negative } \\
\text { Profit }\end{array}$ & Count & Average & $\begin{array}{l}\text { Total } \\
\text { Zero } \\
\text { Profit }\end{array}$ \\
\hline Mar-91 & -887.713 & 30 & -29.5904 & 60.17361 & 4 & 15.0434 & -947.887 & 26 & -36.4572 & 0 \\
\hline Jun-91 & 525.0118 & 10 & 52.50118 & 594.809 & 8 & 74.35113 & -69.7972 & 2 & -34.8986 & 0 \\
\hline Sep-91 & -2357.48 & 71 & -33.2039 & 163.5158 & 5 & 32.70316 & -2520.99 & 66 & -38.1968 & 0 \\
\hline Dec-91 & -3267.67 & 108 & -30.2562 & 487.4149 & 13 & 37.49345 & -3755.08 & 95 & -39.5272 & 0 \\
\hline Mar-92 & -1689.68 & 76 & -22.2327 & 576.8741 & 14 & 41.20529 & -2266.56 & 62 & -36.5574 & 0 \\
\hline Jun-92 & -1938.43 & 68 & -28.5063 & 0 & 0 & 0 & -1938.43 & 68 & -28.5063 & 0 \\
\hline Sep-92 & 331.8885 & 144 & 2.304781 & 3414.901 & 45 & 75.88669 & -3083.01 & 99 & -31.1415 & 0 \\
\hline Dec-92 & -346.456 & 40 & -8.6614 & 1118.904 & 9 & 124.3227 & -1465.36 & 31 & -47.2697 & 0 \\
\hline Mar-93 & -2212.62 & 77 & -28.7354 & 393.1021 & 14 & 28.07872 & -2605.73 & 63 & -41.3608 & 0 \\
\hline Jun-93 & -3346.3 & 106 & -31.5688 & 205.1266 & 5 & 41.02531 & -3551.42 & 101 & -35.1626 & 0 \\
\hline Sep-93 & -6097.95 & 138 & -44.188 & 0 & 0 & 0 & -6097.95 & 138 & -44.188 & 0 \\
\hline Dec-93 & -3558.71 & 79 & -45.0469 & 0 & 0 & 0 & -3558.71 & 79 & -45.0469 & 0 \\
\hline Mar-94 & -2849.51 & 71 & -40.1339 & 19.84893 & 1 & 19.84893 & -2869.36 & 70 & -40.9908 & 0 \\
\hline Jun-94 & -1826.17 & 149 & -12.2562 & 1913.429 & 46 & 41.59628 & -3739.6 & 103 & -36.3068 & 0 \\
\hline Sep-94 & -10955.1 & 305 & -35.9184 & 240.5704 & 20 & 12.02852 & -11195.7 & 285 & -39.2831 & 0 \\
\hline Dec-94 & -6611.33 & 236 & -28.0141 & 876.9749 & 17 & 51.58676 & -7488.3 & 219 & -34.1931 & 0 \\
\hline Mar-95 & -8672.75 & 268 & -32.361 & 941.3809 & 38 & 24.77318 & -9614.12 & 230 & -41.8005 & 0 \\
\hline Jun-95 & 9639.835 & 209 & 46.12361 & 16376.27 & 35 & 467.8936 & -6736.43 & 174 & -38.7151 & 0 \\
\hline Sep-95 & -4449.78 & 111 & -40.0881 & 0 & 0 & 0 & -4449.78 & 111 & -40.0881 & 0 \\
\hline Dec-95 & 2573.716 & 135 & 19.06456 & 6722.296 & 27 & 248.9739 & -4148.58 & 108 & -38.4128 & 0 \\
\hline Mar-96 & 1629.487 & 228 & 7.146875 & 10461.15 & 8 & 1307.644 & -8831.67 & 220 & -40.1439 & 0 \\
\hline Jun-96 & -1012.07 & 159 & -6.36524 & 4328.274 & 6 & 721.3791 & -5340.34 & 153 & -34.9042 & 0 \\
\hline Sep-96 & -3383.22 & 527 & -6.41978 & 15530.46 & 74 & 209.8711 & -18913.7 & 453 & -41.7521 & 0 \\
\hline Dec-96 & 11038.08 & 833 & 13.251 & 40913.9 & 108 & 378.8324 & -29875.8 & 725 & -41.208 & 0 \\
\hline Mar-97 & -21460.2 & 772 & -27.7982 & 4006.288 & 109 & 36.75494 & -25466.5 & 663 & -38.411 & 0 \\
\hline Jun-97 & 74697.27 & 855 & 87.36523 & 95803.59 & 241 & 397.5253 & -21106.3 & 614 & -34.375 & 0 \\
\hline Sep-97 & 7688.196 & 435 & 17.67401 & 19901.87 & 101 & 197.0482 & -12213.7 & 334 & -36.5679 & 0 \\
\hline Dec-97 & 36055.49 & 494 & 72.98682 & 42875.33 & 282 & 152.0402 & -6819.86 & 212 & -32.1691 & 0 \\
\hline Mar-98 & 534927.6 & 483 & 1107.51 & 536097.6 & 409 & 1310.752 & -1170.13 & 73 & -16.0291 & 1 \\
\hline Jun-98 & 394354.8 & 856 & 460.6948 & 398458.8 & 706 & 564.3893 & -4103.79 & 148 & -27.7283 & 2 \\
\hline
\end{tabular}

Table 5 A

$\Re=\left[\mathbf{P}_{\min }, \mathbf{P}_{\max }\right]:$

\begin{tabular}{|c|c|c|c|c|c|c|c|c|c|c|}
\hline \multirow{2}{*}{ RULES } & \multicolumn{2}{|c|}{ RF } & \multicolumn{2}{c|}{ RMC } & \multicolumn{2}{c|}{ RC } & \multicolumn{2}{c|}{$\begin{array}{c}\text { Number of } \\
\text { Recommendations }\end{array}$} & $\begin{array}{c}\text { AVERAGE } \\
\text { PROFIT }\end{array}$ & $\begin{array}{c}\text { TOTAL } \\
\text { PROFIT }\end{array}$ \\
\cline { 2 - 13 } & TRAINING & TEST & TRAINING & TEST & TRAINING & TEST & TRAINING & TEST & TEST & TEST \\
\hline GDT1 & 0.0000 & 0.0000 & 0.6240 & 0.6226 & 0.8499 & 0.8441 & 91 & 60 & 1046.49 & 62789.57 \\
\hline GDT2 & 0.0000 & 0.0000 & 0.5868 & 0.5660 & 0.8588 & 0.8583 & 100 & 69 & 929.54 & 64138.22 \\
\hline GDT3 & 0.0000 & 0.0000 & 0.5992 & 0.5849 & 0.8559 & 0.8535 & 97 & 66 & 968.46 & 63918.51 \\
\hline GDT4 & 0.0000 & 0.0000 & 0.5992 & 0.5849 & 0.8559 & 0.8535 & 97 & 66 & 968.46 & 63918.51 \\
\hline GDT5 & 0.0000 & 0.0000 & 0.6157 & 0.6226 & 0.8519 & 0.8441 & 93 & 60 & 1009.24 & 60554.29 \\
\hline GDT6 & 0.0000 & 0.0000 & 0.5868 & 0.5849 & 0.8588 & 0.8535 & 100 & 66 & 968.46 & 63918.51 \\
\hline GDT7 & 0.0000 & 0.0000 & 0.5992 & 0.5472 & 0.8559 & 0.8630 & 97 & 72 & 904.25 & 65105.89 \\
\hline GDT8 & 0.0000 & 0.0000 & 0.5868 & 0.5535 & 0.8588 & 0.8614 & 100 & 71 & 904.39 & 64211.48 \\
\hline GDT9 & 0.0000 & 0.0000 & 0.5909 & 0.5472 & 0.8579 & 0.8630 & 99 & 72 & 903.54 & 65055.18 \\
\hline GDT10 & 0.0000 & 0.0000 & 0.5868 & 0.5849 & 0.8588 & 0.8535 & 100 & 66 & 968.46 & 63918.51 \\
\hline MEAN & 0.0000 & 0.0000 & 0.5975 & 0.5799 & 0.8563 & 0.8548 & 97.4 & 66.8 & 957.1 & 63752.9 \\
\hline SD & 0.0000 & 0.0000 & 0.0131 & 0.0275 & 0.0032 & 0.0069 & 3.1693 & 4.3665 & 47.64 & 1297.61 \\
\hline
\end{tabular}


Table 5 B

$\Re=\left[P_{\min }, P_{\max }\right]: \quad(10-15)$

\begin{tabular}{|c|c|c|c|c|c|c|c|c|c|c|}
\hline \multirow{2}{*}{ RULES } & \multicolumn{2}{|c|}{ RF } & \multicolumn{2}{c|}{ RMC } & \multicolumn{2}{c|}{ RC } & \multicolumn{2}{c|}{$\begin{array}{c}\text { Number of } \\
\text { Recommendations }\end{array}$} & $\begin{array}{c}\text { AVERAGE } \\
\text { PROFIT }\end{array}$ & $\begin{array}{c}\text { TOTAL } \\
\text { PROFIT }\end{array}$ \\
\cline { 2 - 13 } & TRAINING & TEST & TRAINING & TEST & TRAINING & TEST & TRAINING & TEST & TEST & TEST \\
\hline GDT1 & 0.0000 & 0.0000 & 0.4752 & 0.4591 & 0.8857 & 0.8850 & 127 & 86 & 771.68 & 66364.11 \\
\hline GDT2 & 0.0338 & 0.0100 & 0.4091 & 0.3774 & 0.8966 & 0.9039 & 148 & 100 & 668.46 & 66846.35 \\
\hline GDT3 & 0.0000 & 0.0000 & 0.4380 & 0.4465 & 0.8946 & 0.8882 & 136 & 88 & 753.78 & 66332.20 \\
\hline GDT4 & 0.0726 & 0.0500 & 0.5248 & 0.5220 & 0.8648 & 0.8630 & 124 & 80 & 842.08 & 67366.07 \\
\hline GDT5 & 0.0000 & 0.0000 & 0.4959 & 0.4780 & 0.8807 & 0.8803 & 122 & 83 & 796.08 & 66074.30 \\
\hline GDT6 & 0.0000 & 0.0000 & 0.5165 & 0.4843 & 0.8757 & 0.8787 & 117 & 82 & 804.37 & 65958.05 \\
\hline GDT7 & 0.0152 & 0.0112 & 0.4628 & 0.4465 & 0.8867 & 0.8866 & 132 & 89 & 744.31 & 66243.73 \\
\hline GDT8 & 0.0877 & 0.0286 & 0.5702 & 0.5723 & 0.8529 & 0.8535 & 114 & 70 & 892.51 & 62475.56 \\
\hline GDT9 & 0.0000 & 0.0000 & 0.5207 & 0.4969 & 0.8748 & 0.8756 & 116 & 80 & 826.75 & 66140.26 \\
\hline GDT10 & 0.0000 & 0.0000 & 0.4669 & 0.4591 & 0.8877 & 0.8850 & 129 & 86 & 770.43 & 66256.81 \\
\hline MEAN & 0.0209 & 0.0100 & 0.4880 & 0.4742 & 0.8800 & 0.8800 & 126.5 & 84.4 & 787.0 & 66005.7 \\
\hline SD & 0.0333 & 0.0168 & 0.0472 & 0.0515 & 0.0135 & 0.0139 & 10.3950 & 7.7201 & 61.12 & 1308.05 \\
\hline
\end{tabular}

Table $5 \mathrm{C}$

$\Re=\left[\mathbf{P}_{\min }, \mathbf{P}_{\max }\right]$ :

(15-20)

\begin{tabular}{|c|c|c|c|c|c|c|c|c|c|c|}
\hline \multirow{2}{*}{ RULES } & \multicolumn{2}{|c|}{ RF } & \multicolumn{2}{c|}{ RMC } & \multicolumn{2}{c|}{ RC } & \multicolumn{2}{c|}{$\begin{array}{c}\text { Number of } \\
\text { Recommendations }\end{array}$} & $\begin{array}{c}\text { AVERAGE } \\
\text { PROFIT }\end{array}$ & $\begin{array}{c}\text { TOTAL } \\
\text { PROFIT }\end{array}$ \\
\cline { 2 - 13 } & TRAINING & TEST & TRAINING & TEST & TRAINING & TEST & TRAINING & TEST & TEST & TEST \\
\hline GDT1 & 0.3415 & 0.3077 & 0.4421 & 0.4340 & 0.8241 & 0.8283 & 205 & 130 & 420.91 & 54718.71 \\
\hline GDT2 & 0.2199 & 0.2031 & 0.3843 & 0.3585 & 0.8658 & 0.8693 & 191 & 128 & 521.28 & 66723.61 \\
\hline GDT3 & 0.2135 & 0.2214 & 0.3760 & 0.3585 & 0.8688 & 0.8646 & 192 & 131 & 508.36 & 66595.46 \\
\hline GDT4 & 0.2414 & 0.2241 & 0.4545 & 0.4340 & 0.8489 & 0.8504 & 174 & 116 & 388.43 & 45057.48 \\
\hline GDT5 & 0.2513 & 0.3023 & 0.3967 & 0.4340 & 0.8559 & 0.8299 & 195 & 129 & 515.24 & 66465.95 \\
\hline GDT6 & 0.1623 & 0.1500 & 0.3388 & 0.3585 & 0.8877 & 0.8819 & 191 & 120 & 560.20 & 67223.75 \\
\hline GDT7 & 0.2246 & 0.2593 & 0.4008 & 0.3711 & 0.8618 & 0.8520 & 187 & 135 & 491.91 & 66408.02 \\
\hline GDT8 & 0.2328 & 0.2188 & 0.4008 & 0.3711 & 0.8598 & 0.8630 & 189 & 128 & 519.97 & 66555.53 \\
\hline GDT9 & 0.2083 & 0.2406 & 0.3719 & 0.3648 & 0.8708 & 0.8583 & 192 & 133 & 499.77 & 66469.69 \\
\hline GDT10 & 0.1961 & 0.2391 & 0.3223 & 0.3396 & 0.8827 & 0.8630 & 204 & 138 & 488.41 & 67401.27 \\
\hline MEAN & 0.2292 & 0.2366 & 0.3888 & 0.3824 & 0.8626 & 0.8561 & 192.0 & 128.8 & 491.4 & 63361.9 \\
\hline SD & 0.0467 & 0.0462 & 0.0407 & 0.0366 & 0.0179 & 0.0167 & 8.7050 & 6.5794 & 50.50 & 7464.85 \\
\hline
\end{tabular}

Table 5 D

$\Re=\left[\mathbf{P}_{\min }, \mathbf{P}_{\max }\right]$ :

$(20-25)$

\begin{tabular}{|c|c|c|c|c|c|c|c|c|c|c|}
\hline \multirow{2}{*}{ RULES } & \multicolumn{2}{|c|}{ RF } & \multicolumn{2}{c|}{ RMC } & \multicolumn{2}{c|}{ RC } & \multicolumn{2}{c|}{$\begin{array}{c}\text { Number of } \\
\text { Recommendations }\end{array}$} & $\begin{array}{c}\text { AVERAGE } \\
\text { PROFIT }\end{array}$ & $\begin{array}{c}\text { TOTAL } \\
\text { PROFIT }\end{array}$ \\
\cline { 2 - 13 } & TRAINING & TEST & TRAINING & TEST & TRAINING & TEST & TRAINING & TEST & TEST & TEST \\
\hline GDT1 & 0.4492 & 0.4346 & 0.3058 & 0.3208 & 0.7903 & 0.7890 & 305 & 191 & 415.20 & 79303.87 \\
\hline GDT2 & 0.4023 & 0.3734 & 0.3554 & 0.3774 & 0.8101 & 0.8126 & 261 & 158 & 495.89 & 78351.04 \\
\hline GDT3 & 0.4580 & 0.4302 & 0.3595 & 0.3585 & 0.7833 & 0.7890 & 286 & 179 & 442.11 & 79137.55 \\
\hline GDT4 & 0.2520 & 0.1753 & 0.2397 & 0.2013 & 0.8807 & 0.9071 & 246 & 154 & 731.71 & 112683.86 \\
\hline GDT5 & 0.3730 & 0.3554 & 0.3471 & 0.3270 & 0.8231 & 0.8252 & 252 & 166 & 397.27 & 65947.63 \\
\hline GDT6 & 0.3373 & 0.3092 & 0.3182 & 0.3396 & 0.8400 & 0.8409 & 249 & 152 & 439.22 & 66760.98 \\
\hline GDT7 & 0.4633 & 0.4462 & 0.3058 & 0.3208 & 0.7823 & 0.7827 & 313 & 195 & 406.01 & 79171.06 \\
\hline GDT8 & 0.4498 & 0.4353 & 0.3884 & 0.3962 & 0.7863 & 0.7843 & 269 & 170 & 459.08 & 78043.79 \\
\hline GDT9 & 0.3485 & 0.3770 & 0.2893 & 0.2830 & 0.8390 & 0.8205 & 264 & 183 & 430.58 & 78796.89 \\
\hline GDT10 & 0.4327 & 0.4167 & 0.3554 & 0.3396 & 0.7962 & 0.7969 & 275 & 180 & 436.09 & 78497.09 \\
\hline MEAN & 0.3966 & 0.3753 & 0.3264 & 0.3264 & 0.8131 & 0.8148 & 272.0 & 172.8 & 465.3 & 79669.4 \\
\hline SD & 0.0687 & 0.0827 & 0.0433 & 0.0542 & 0.0324 & 0.0380 & 23.0314 & 15.1936 & 97.68 & 12701.92 \\
\hline
\end{tabular}

Table 5 A-D Constraint FGP Runs for Different $\mathfrak{R}=\left[P_{\min }, P_{\max }\right]$ 